\title{
ERP Implementation and Interoperability Growth as Organization Improvement Agents in Public Administration Further Development
}

\author{
Darko Lugonja \\ Ratarska 35, Zagreb, Croatia
}

dlugonja@foi.hr

\begin{abstract}
Further public administration development depends on numerous various influences stakeholders' and public needs, so when planned to be developed, implemented or improved, they have to be carefully considered. ERP and/or other system need to be incorporated according to specific conditions. Interoperability represents strong support for implementation, integration or further development for public administration. This paper aims for contribution to awareness growth and platform for further work. Considering various case studies, ERP implementation, interoperability, critical success factors and contingency approach, paper aims for further development in this area. ERP becomes a platform for further ICT development towards quantum computing.
\end{abstract}

Keywords: Public administration, development, ERP, interoperability, CSF, contingency approach, quantum computing

\section{Introduction}

ICT systems are supporting public sector towards further development and competitiveness intensification. In order to improve efficacy and efficiency across the system, to reduce inadequate resources utilization, to improve functionality by implementing advanced information systems, government institutions have focused towards implementing complex solutions, such as enterprise resource planning (ERP) systems.

ERP is expected to ensure the most appropriate solution for numerous, various and growing governmental information requirements, to improve their competitiveness. There are still doubts whether those systems represent the most appropriate solution for the public sector with its traditional, fragmented organizational structure and culture.

This paper aims to discuss upon the information systems strategy, considering also a 'critical success factor' model. Various case studies were considered and conducted in the process of implementing ERP systems. Various specific complexities, political, cultural or technical ones have been considered, being aware of the public sector traditional structure. 
According to the cases' studies and findings, author would like to suggest a careful use of communication and change management procedures, to ensure an appropriate implementation of ERP systems and institutional / organizational interoperability, so to propose an appropriate solutions for some of the problems. Science, professional, organizational and technology trends in business and development are adding to ERP influence and growth, not only in implementation, but also in connection to various relevant areas, previously less recognized or acknowledged.

Public sector improvement by ERP implementation and interoperability recognition, growth and improvement, are popular, various scientific articles and research projects were performed during the past few decades, but there are still uncovered areas, namely building awareness and connecting those topics to interoperability. The final point is, ensuring the platform for further research and works on ERP implementation and interoperability. As we are considering public administration as a huge growth potential for economy (in EU near one quarter of employees are employed in public sector), we have to ensure the platform for building awareness and development point for further activities and initiatives.

EU public sector, as a large and complex system, processes millions of various activities (administrative, financial, legal, organizational etc.), so they need an adequate ICT, as well as all kind of other support systems and activities, in order to ensure basic set of services and activities. Once there are announced improvements and further developments, so called "administration reform", there are additional efforts, needed for preparation and implementation. Technical support for outdated local IT systems is one of critical issues, insufficient number of highly educated experts and financial limitations reducing IT budgets to basic maintenance, resulted in low and inadequate efforts, results and outputs. There is strong need for new IT projects and developments meeting planned budgets, goals, programs and strategies.

This paper aim is also to support development of the new and flexible public services system architecture that will incorporate an appropriate ERP system in public administration. Planning ERP have to include implementation, scope definition, budget estimation, program and project approval, preparation, tender, proposals evaluation and contract realization. Once contract and organization are defined, the next step is project activities start - a realization, according to previously approved plans and activities. In order to ensure successful implementation and further steps, public sector needs set of an adequate strategies and legal framework that will support system with strict legal requirements. There are still sensitive areas that have to be carefully covered:

- management processes: budget control, risk management, steering committee meetings, etc.,

- $\quad$ tracking planned timeframe, searching for eventual new risk sources and

- $\quad$ establishment of special experts and crisis management team for urgent problems solving,

- $\quad$ vendor negotiations preparing,

- $\quad$ preparing alternatives for unplanned change requests,

- $\quad$ ensuring continuous financial flows, and

- $\quad$ the most suitable monitoring system establishing and performing. 


\section{Case Studies on the Interoperability and ERP Public Sector Implementation}

This paper aim is to describe the ERP implementation and its influence to public administration improvement and development, as well as relation to interoperability improvement. Author has studied various case studies, to describe various aspects of ERP implementation and its influence to public administration development.

Various specific conditions and experiences from the large organizations and systems, governmental administration or public sector in general, need an appropriate approach that will ensure elements of new business and information system paradigm, so to enable leaders, society, science and economy to find the most suitable solution for contemporary organizational issues and challenges.

Considering public sector ERP implementation, researchers may find available great examples for successful implementation in USA, UK, Scandinavian and Baltic countries, as well as other EU and non EU countries that succeeded in integration and interoperability issue solving, in private companies, but also in public administration.

\subsection{ERP Public Sector Implementation - Case 1}

\section{Rainer Sommer: Public Sector ERP Implementation: Successfully Engaging Middle- Management [1].}

Following to studies and works of Rainer Sommer, there are strong evidences that ERP implementation issues often occur due to cultural problems settled deep inside the organizational structure. Furthermore, in his opinion, public administration suffers from highly departmentalized (referred to as "stove-piped") organizations, averse to the open flow of information and to process oriented management solutions [1]. His paper focuses on the important role of middle management, so to support and advocate an ERP project in the pre-planning and requirements definition phase of a project.

Rainer conducted a research and identified high value middle management attributes that need to be identified by ERP project managers to co-opt these individuals into the role of "trusted intermediaries", acting as managerial bridges between traditional organizational "stovepipes". Since the 1990's many public sector organizations have followed the private sector and implemented pre-packaged commercial Enterprise Resource Planning (ERP) solutions [1].

Although ERP software may not exactly support all complex business processes, public sector organizations were eager to trade-off complex domain specific functionality for the benefits gained from a pre-packaged enterprise information system. By not developing a proprietary solution, the expectation was towards significant cost savings and increased organizational efficiency [1]. The number of public sector ERP implementations has risen rapidly in recent years. Implementations were successful in significant part of administrations, but, there were also many failures, due to difficulties in defining the scope, management and implementation in accordance with the best industry practices and generally accepted project management principles [1]. 
What is ERP? According to Sommer, ERP (Enterprise Resource Planning) represents a process-oriented management view with regard to organizational realignment [1]. Sommer made the comparison between public and private sector business transformation, as driven by "cross-intentionally reducing the functional requirements of the ERP system to meet timeline and budget mandates" [1]. Previous management transformation efforts have failed due to outdated process structures that often operate under conflicting governance models.

In addition, public and private sector management cultures are all too often wedded to traditional planning methods that run contrary to modern customeroriented management practices. Accordingly, ERP have to be considered within the context of a management paradigm as well as a business software application view, it makes sense to trace its lineage [2] [1].

Sommer conducted this research with the idea to "gauge the importance of middle management in the successful implementation of an ERP system". This paper is based upon information collected through qualitative methods (interviews, literature review and direct project work by the author on federal government ERP projects) [1].

Sommer presented significant differences in public and private sector organizational structures:

- public sector managers are making decisions upon a consensus (historically and from security perspective, this is a valid model, that has stood the test of time, excluding an absolute power position),

- public sector organizations have no strict bottom line incentives (profit, customer satisfaction, or competitive advantage),

- these concepts have a different meaning than in the private sector

- unclear picture upon the "true" public sector customer, because there are no direct "payments for services", as a baseline for performance measuring [1].

Public sector organizations are suffering from leaders' shortage, for successful link of the vision and political capital to achieve that vision, as well as highly successful project managers.

Political appointees most often aren't supported with a time frame long enough to support an agenda. Their initiatives are usually limited into 3-4 years. There is also a fact that many senior officers are seriously depending on mandatory rotation, hence, regardless of their agenda, their programs are funded and completed in the mentioned time frame. Public sector mid-level managers usually are able to delay projects and activities incomparably longer than private sector mid-level management. Innovative thinking in the public sector not encouraged or rewarded [1].

ERP implementation may be easily driven over budget, because the most of decisions are depending on consensus. ERP systems success in the private sector influenced public sector organizations to enhance process management and cost reduction solutions. Middle management prospered from control position over processes and information flows. ERP may be considered as a challenge to their authority and position [1]. 


\subsection{ERP public sector implementation - case 2}

Goran Hajdin, Neven Vrček. Methodologies for Measuring E-Government Development: The Croatian Case [3]

Contemporary public sector governance opens various questions and development areas, particularly considering ERP implementation. Additional importance was given to the development and network connecting of various platforms for e-services and e-government solutions. EU, USA, as well as national governments are pushing agenda for ERP implementation and further changes that will support society development according to growing number and type of challenges. That represent rising potential for rapid growth and development, and innovation in various related areas.

This paper focus was on Croatia and differences between methodological approaches to measurement of e-services benefits and results, and their coherence for comparison [4]. Authors conducted analysis on Croatian public administration and eservices and their role in e-government development. In order to support the analysis and approve the findings, they have studied methodology and considered timeline, as well as state of the art in the few decades overview [5] [3].

E-government initiatives started in late 1990's and have officially started to develop in 2003 with the "e-Croatia 2007" project start [4]. To accomplish this task internal measurement methodologies have been developed, which relay on EU guidelines and practices. This allows the government and responsible bodies to compare results with similar projects in Europe [4] [6].

Different countries have developed their own methodologies and measuring upon accomplishments and progress of set e-government strategies and goals while implementing and developing e-services. [4] [7] [3] Authors have considered also a "Global E-Government" [6], as a project conducted by Brookings Institution, focused on economic studies, foreign policy, global economy and development, governance studies and metropolitan policy programs [4]. Global E-Government has collected data from 1,687 national government websites from 198 different countries all over the world [4]. Their methodology was based on evaluation of stated websites by criteria of: "information availability, service delivery and public access". Authors have presented top-ten countries in those reports, including ranking for Croatia (on $45^{\text {th }}$ position in 2007). In the same report Croatia is stated to have $60 \%$ of online services covered by websites, from which $100 \%$ have publications online, $80 \%$ of them have some sort of databases and $20 \%$ have privacy policy as well as security policies. From those pages $0 \%$ was adopted to W3C disability accessibility standards [8].

This study also presents differences among world regions. In 2006 average score for Eastern Europe was 30\%, while in 2007 it was 32\% [9]. Focusing back on Croatia, it scored below average in year 2006 with $28 \%$, but made a big leap in next year where the score was above average (35\%). This study was conducted on 198 countries from all over the world [6]. 
Additionally, authors have considered also "UN e-Government survey" [10] that included much more holistic approach. The methodology was based on infrastructure development, human capacity, access to knowledge and information. Since governments are viewing their citizens as "customers" this methodology is also more focused on government-to-citizen (G2C) approach, becoming more common in this field. Their questions were focused on " 21 citizens' informative and participatory services" which are grouped in 3 categories: "e-information, e-consultation and edecision-making" [10]. UN survey was conducted on 192 countries from all over the world. Croatian final 47th place was calculated from 3 main categories in UN survey: Web measure index where Croatia had 0.43 , infrastructure index with a result of 0.37 and human capital index of 0.9 . As stated, Croatian e-government readiness index was $0.57[4]$.

When considering methodology as a key approach to projects and case studies, authors have also studied Mareva methodology as a method for analysis of impact of various government e-services, based on "return on investment (ROI) calculations for large public projects and comparable approaches in the private sector" [11]. Furthermore, they considered Value Measuring Methodology (VMM) [7], based on defining, capturing and measuring values associated with e-services not accounted in ROI [7]. They also considered rank in 2008 WiBe methodology [12], based on economic efficiency assessment with particular focus on e-administration elements. WiBe has 3 main areas of impact. First one is "Monetary economic efficiency" which is divided into two subcategories of "Benefits" and "Costs" for a project. Second area is "Extended economic efficiency" which is also divided into two subcategories of "Urgency of the measure" and "Qualitative, strategic importance". Last area is related to "Economic efficiency from an external point of view" and is considered to be an optional part of WiBe methodology. Worth mentioning is that WiBe methodology is used in German Government and administrative bodies [12].

Authors have focused onto methodologies' differences, data collection and analysis related to e-government projects and services. As we have witnessed, that area had dynamic development in the past decade, as many countries have developed and implemented e-government solutions [3]. As there are limits in resources, in order to avoid high costs and time consuming methodologies, there are necessary activities needed to ensure accurate results, respectful to resource constraints and country priorities. Accordingly, authors were focused onto the use of e-service documents and strategies which greatly influence the way e-services have been developed in various countries and set the criteria for their evaluation [12].

\subsection{ERP Public Sector Implementation - Case 3}

\section{Jukka Hemilä, Information Technologies for Value Network Integration [13]}

Author described enterprise networks as a set of potentially successful approaches for increasing competitivenes, based on their core business, created partnerships and linear supply chains of companies. 
We may consider study objectives as: (1) definitions of suitable applications for networked enterprises, supply chains managing, and application integration, (2) proposition of information sharing for the company's use and with the business partners, (3) creation of a hypothetical model for value network integration by combining the research results [13].

Hemilä conducted research on literature, interviews and questionnaires, Internet available information, software vendors' interviews, in order to support hypothesis and contribute to model and approach development. Author performed combination of qualitative and quantitative analysis, applying few methods in order to ensure representative output and results with combined approach - qualitative and quantitative, literature, paradigms and models analysis [13].

The key thesis of the study was that the use of information technologies will improve co-operation and communication between networked enterprises. Another assumption of the study is that interaction and integration between different solutions could be possible.

The main assumptions were, when considering cooperation between networked enterprises, we take into account processes between enterprises. Also, there is a strong need for a process map, how enterprises act in a network and what the main processes in the business between networked enterprises are, and, there is a need for a model for the value network, with supply chain and network management [13].

Following the Hemilä's findings and works, researchers have to consider ERP implementation in large system and its contribution to enterprise networks, as a platform for further integration and development, not only on the corporate level, but also from the larger network perspective [13].

Considering value network integration and Hemilä contribution towards building a model or a platform for future research, there are great chances to approve his conclusions and findings. Accordingly, integration throughout ERP system ensures success, particularly when the core businesses and organizations share similar values and goals [13].

\subsection{ERP Public Sector Implementation - Case 4}

William Wagner, Yvonne Lederer Antonucci, An Analysis of the Imagine PA Public Sector ERP Project [14]

Authors have studied organizations' changes through streamlining their business processes enabled by enterprise resource planning (ERP) systems during the past few decades. They distinguished private sector ERP implementation and public sector, according to specific characteristics and structures. Also, they conducted a research on large organizations across the USA and their ERP implementations.

Several government agencies implementing small-scale ERP projects, have reported that the integration of agencies and systems in the public sector can be quite different from the private sector, requiring the use of a different approach and model [14]. 
Authors questioned upon "a need to use a different enterprise systems implementation approach and model for a large scale integrated ERP system in the public sector compared to the private sector.

This paper was focused onto differences identification in ERP implementation methodologies deployed in the public and private sectors, and discussion upon the issues and success factors of the Imagine PA1 ERP project, compared to private sector ERP implementations" [14].

There are great examples of ERP implementation in various circumstances, and authors contribution, apart from article provided, also in presentation - figure of ERP generalized implementation approach [14].

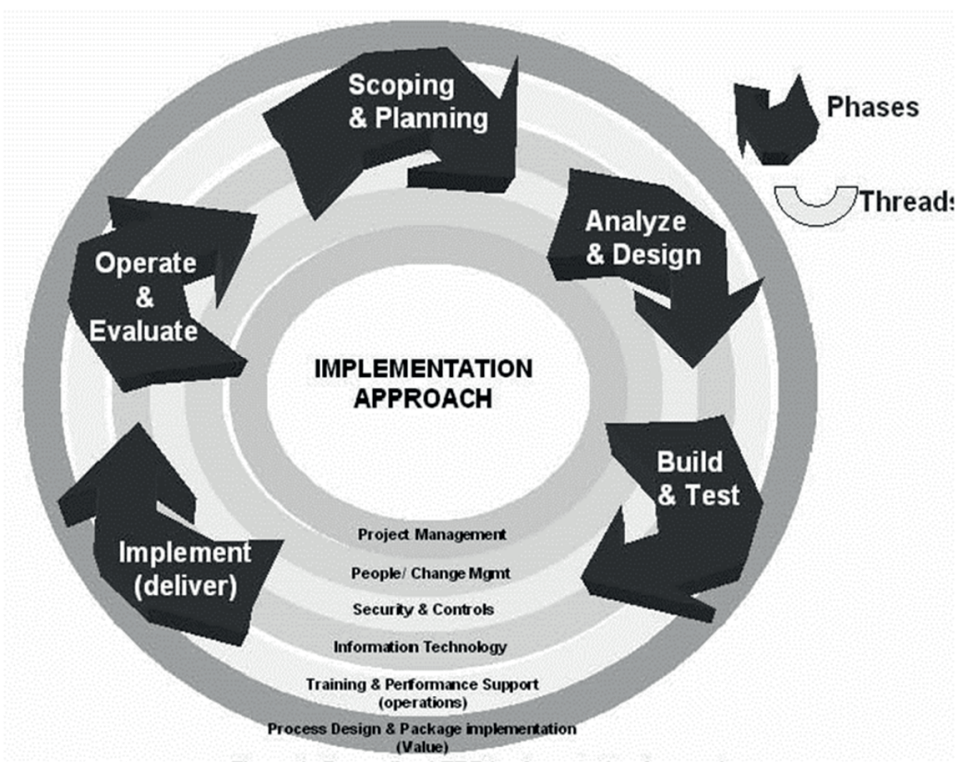

Figure 1: Generalized ERP Implementation Approach, Source: William Wagner, Yvonne Lederer Antonucci, An Analysis of the Imagine PA Public Sector ERP Project, USA 2004 [14].

Authors have analyzed critical differences between the public and private sector, in organizational structure, project teams and their complexity, culture and dynamics, included literature and case studies overview, in order to present the state of the art in each sector [15]. They considered differences according to comparison of ERP implementations between both sectors, so they have studied case studies and literature, relevant for their study and found several areas described as different.

As in Sommer paper and cited authors they have found culture as the critical difference, mostly related to the beginning phases of ERP implementation. [16] [1]. Another critical point was organizational structure, being more complex and departmentalized, having so many organizational levels, structure elements and subelements, managers, orders, processes and rules [14]. 
Generalized ERP Implementation Approach intensifies the challenge in obtaining top management commitment (Watson et. al., 2003; Chang et. al., 2001) [17] [18].

In addition, the political composition of many government agencies in the US can change frequently affecting the leadership and objectives of the project, creating a challenge for maintaining a large-scale ERP implementation focus and top management commitment (Watson et. al., 2003) [17]. Additionally, there are issues in interaction of process owners and consultants (Blick et. al., 2000) [2]. Public sector project team dynamics also has shown differences in compare to private sector, as they are also larger and more complex, not the small ones as in private sector, consisting 3-5 members (1-2 consultants and 2-3 managers from the business), public sector project teams are more structured, in order to represent each unit, division or department, due to their position in organization [14].

As an example, authors presented the case study of the ERP implementation at Multnomah County, Oregon - they had a project team of 43 county employees and 17 employees from their implementation partner for a financial and payroll implementation of 1200 end users (Boyer, 2001) [16] [14]. There were also significant differences in source funding source differences, indicating that government agencies have very complex budgeting and allocation processes (Makulowich, 1999) [19]. Authors found that most public sector organizations on a worldwide scale share similar requirements, however each country tends to have unique differences [20] [21]. This creates a difficulty in defining "best business practices" for the public arena [14].

There are also serious disadvantages regarding public sector organizational complexity and numerous organizational units, combined with a large number of users across many ERP modules, making public sector ERP implementation impossible to adopt the commercial processes (Blick et. al, 2000) [2].

There are requests for additional time, as there are gaps generated during design and analysis phase throughout the implementations each phase. Analyzing those gaps may lead to definition of changes and levels of changes, considering the framework, resources and limitations. After analyses and designing the changes, processes, phases, roles and other components of implementation, differences between public and private sector are becoming smaller and less significant, similarities more often and significant.

In fact they appear to be the same from a purely technical perspective (Blick et. al., 2000) [2]. "ERP implementation requires a significant increase in time dedicated to the initial phases of an ERP implementation project (Scoping \& Planning; Analysis \& Design), but that the core implementation (Build \& Test; Implement; Operate \& Evaluate) is similar to the private sector. An initial analysis of the Imagine PA study seems to support this [14].

Considering ERP implementation in public sector organizations, project planners and managers need "tailor made" approach and additional time, due to public sector system complexity. As ERP implementation is already global trend, there are initiatives in various organizations, in order to ensure systematic and standardized development. [14]. 
The ERP implementation approach, according to Blick et al. [2], must have the different rules for the private and public sector, because, even when the private sector ERP implementation methods are appropriate for largescale public sector ERP implementations, there are still significant differences that have to be specified, even quantified, in order to ensure planned results and outcome [14]. Authors have found that much of the private sector ERP implementation methodology was similar to public sector ERP implementations for the Commonwealth of Pennsylvania, but also they have found that the best practices were also very similar with some organizational differences. This leads to conclusion upon the further need for additional analysis and studies of possible differences between public and private sector ERP implementations in order to determine if the ERP implementation structure utilized in the private sector for large-scale ERP projects is appropriate for the public sector. Just as in the private sector, one measure of the success of this ERP implementation will be how much the commonwealth can leverage their newly integrated processes and improve the quality of public sector decision-making and also build more effective eGovernment applications off of it [14].

\subsection{ERP Public Sector Implementation - Case 5}

Mohammad Reza Moohebat, Asefeh Asemi, Mohammad Davarpanah Jazi: A Comparative Study of Critical Success Factors (CSFs) in Implementation of ERP in Developed and Developing Countries [22]

Considering ERP implementation specifics, not only in the private and/or public sector, there are also specific differences amongs countries, particularly related to cultures, and social-economic development. Authors have conducted research and analysis upon the differences of Critical Success Factors (CSFs) in implementation of ERP in developed and developing countries. Also, they have provided relevant information upon the historical point and trends related to future implementations. CSF in ERP implementation is defined as "factors needed to ensure a successful ERP project".

Gartner Institute described ERP as Business strategies and enabling software that integrate manufacturing, financial and distribution functions to dynamically balance and optimize enterprise resources. ERP software suites include integrated manufacturing, distribution and financial applications [23]. ERP ensures enterprises business processes and analysis capabilities optimization in order to achieve speed and efficiency [22]. It is estimated that 300 billion dollars were spent on ERP systems during the 1990's [24]. However, the implementation of ERP is a complex process, and many adopters have encountered problems in different phases [25].

Robbins-Gioia surveyed 236 companies in 2001 finally revealed that $51 \%$ of ERP projects are unsuccessful [26]. When considering CSF (Critical success factor), we take into account the definition of success - it depends on the point of view of the person who defines it. It became clear early on in the research that people often mean different things when talking about information systems or ERP success [27] [28]. 
In information systems implementation research, there has been a lot of attention given to measuring "success" in implementation [29]. In a broad approach, he focused on industry-related CSFs which are relevant for any company in a particular industry [30]. Bruno and Leidecker [31] define CSF as "those characteristics, conditions or variables that, when properly sustained, maintained, or managed, can have a significant impact on the success of a firm competing in particular industry". Today CSF approach applies in different subjects such as project management, based on Ramaprasad and Williams [32] survey, CSF approach uses in three major area include project management (63.49\%), IS implementation (49.21\%), and requirements (47.62 \%). Critical Success Factors (CSFs) approach was first used by Rockhart [33] in IS area [34]. Many researchers have tried to identify critical success factors that affect ERP implementation [35] [36] [29].

This study objective was to discover key differences between ERP's Critical Success Factors (CSF) in developed and developing countries or not. The study confirmed thesis that during the ERP implementation CSFs are not much different in developed and developing countries but still there are undeniable differences. Obviously, developing countries national culture had significant impact to ERP implementation in those countries. Additionally, in developing countries companies were more dependent on ERP vendors, in compare to companies in developed countries. Recently, there were many studies conducted upon CSF in ERP implementation, but this study was the first onte to explore between developed and developed countries [22].

Authors' findings confirmed results of Huang and Palvia study that have compared ERP implementation in developed and developed countries that declared technology faces additional challenges in developing countries related to economic, cultural and basic infrastructure issues [37]. In addition Rajaspakse identified high cost, culture, integration and lack of knowledge as four factors that make ERP unsuitable for many organizations in Sri Lanka and Asia [38]. These cases show cultural issue is very important factor that differentiate developed and developing countries in ERP implementation. This study revealed that ERP implementation's CSF in both developed and developing countries almost behave in similar pattern. But we should not forget the national culture of developing countries because ERP technology has evolved in developed countries and includes the culture of developed countries implicitly [38] [22].

\subsection{ERP Public Sector Implementation - Case 6}

\section{Wided Guédria, David Chen, Yannick Naudet. A Maturity Model for Enterprise Interoperability [39]}

Authors have conducted study upon interoperability maturity models and concluded that they are covering only some interoperability aspects. Their paper proposed a maturity model for enterprise interoperability which is elaborated on the basis of existing ones. 
They considered the Enterprise Interoperability Framework under the standardization process, their paper reviewed existing maturity models for interoperability (at the time of the research conducted) and recalls the basic concepts of the Enterprise Interoperability Framework. Their proposal included model analysis and they discussed it to the details, presented methodology and metrics for maturity levels, and finally, presented conclusions and perspectives for future work. By implying interoperability as a value, authors implied establishing an adequate measure of merit to evaluate the degree of interoperability [39].

Considering maturity as one of the possible measures, and the evolution stages towards higher degree of interoperability, authors presented systematic work upon the interoperability maturity assessment that may ensure organization insight into their strengths and weaknesses in terms of ability to interoperate with others, and defining priorities to improve interoperability. There are many maturity models, but few of them were developed for interoperability assessment.

This paper and research aim was to propose a Maturity Model for Enterprise Interoperability (MMEI) which deals with all major aspects of interoperability and covers the main concepts of existing interoperability maturity models [39].

The Framework for Enterprise Interoperability (FEI) was initially elaborated in INTEROP NoE [40] and passed CEN/ISO standardization process (CEN/ISO 11354) used as a basis to build this MMEI. Previously, survey and comparison studies [39] [41] have been performed to evaluate existing interoperability maturity models: LISI (Levels of Information System Interoperability) [42], OIM (Organizational Interoperability Model) [43], LCIM (Levels of Conceptual Interoperability Model) [44], and EIMM (Enterprise Interoperability Maturity Model) [45], as well as ISO/15504 (SPICE) [46], although it is not dedicated to A Maturity Model for Enterprise Interoperability 217 interoperability assessment.

The most of interoperability maturity models focus, in most of cases, on one simple facet of interoperability (data, technology, conceptual, Enterprise modeling, etc.). They are complementary rather than contradictory. Consequently it is necessary to structure them into a single complete interoperability maturity model to avoid redundancy and ensure consistency. Author's ambition in this paper was to present a preliminary research result on the development of such a Maturity Model for Enterprise Interoperability.

Main relevant interoperability maturity models are mapped to the framework to evaluate their coverage. The Framework for Enterprise Interoperability [47] defines 3 basic dimensions as follows:

- the content of interoperation at various levels of the enterprise (data, service, process, business),

- barriers, identifying various obstacles in three categories (conceptual, technological, and organizational),

- an approach, representing the ways in which barriers can be removed (integrated, unified, and federated).

Organization that need to be able to properly interoperate with others, use various different tools such as guidelines or metrics as useful. 
Evaluating its interoperability potentiality using the MMEI allows the probability it has to support efficient interoperations, as well as to detect precisely the weaknesses that may become sources of interoperability issues [39].

MMEI defines four levels of interoperability maturity, each one describe a certain degree of capability to establish and/or to improve interoperability [39]:

- Level 0 (Unprepared), this is the initial level of interoperability maturity, characterized by closed systems, where resources are not meant to be shared with others.

- Level 1 (Defined), where the systems are still entirely distinct, some ad hoc interoperations can take place, but the interoperability remains very limited. Some basic IT devices are connectable.

- Level 2 (Aligned), requires that the company is able (i.e. has the capabilities) to make changes in its system in order to adhere to common formats (imposed by a partner).

- Level 3 (Organized), the enterprise is well organized to deal with interoperability challenges. Interoperability capability is extended to heterogeneous systems, and often in a networked context.

- Level 4 (Adapted), corresponds to the highest level of interoperability maturity (universal). Companies are able to dynamically adjust and accommodate 'on the fly' [39].

The maturity in this context was evaluated only from the interoperability point of view and can't be applied for other purpose. High level degree of interoperability can't be achieved for free, as it is costly and time consuming, so each enterprise must define its needed interoperability requirements and planned maturity level. It is not recommended to all enterprise to look for the highest interoperability level regardless of their needs. Authors have proposed the development of a maturity model for enterprise interoperability, with 5 levels of maturity and metrics defined and described.

A Maturity Model for Enterprise Interoperability concerns (data, service, process, and business) and the three main problem areas (conceptual, technical, and organizational) were usually dealt by separated distinct maturity models. According to author's proposals, future work is planned to refine the proposed model and metrics. MMEI is also based on the concepts and notions coming from general system theory, considered as relevant to develop a science base for enterprise interoperability [48]. The MMEI is intended to be used in association with OoEI (Ontology of Enterprise Interoperability) [49] to develop a knowledge based system to support enterprise interoperability analysis and diagnostics [39].

\subsection{ERP Public Sector Implementation - Case 7}

Jörg Ziemann Architecture of Interoperable Information Systems. An Enterprise Model-Based Approach for Describing and Enacting Collaborative Businesss Processes [50] 
Author claims that complex networks describe a wide range of systems in nature and society. Various examples are including the cell, a network of chemical reactions, and the Internet, a network of routers and computers connected by physical links.

Following the work on interoperable information systems conducted in European Research Projects in 2010 the Architecture of Interoperable Information Systems (AIOS) was published as a reference for the construction of interoperating systems and model-based enactment of collaborative business processes [50]. The main elements of the AIOS are:

1. A different data types included in interoperable information system, their relationships, called the structure static part of the architecture, leading organizations to information elements they have to ensure to their partners and how to correlate optimally each element.

2. A different implementing approaches or interoperable information systems adjusting, i.e. - the architecture dynamic part, so to lead organization, to develop the elements mentioned above iteratively.

3. Technical components concept, architecture implementation aimed - design tools and repositories.

The AIOS is reference architecture for the interoperable enterprise information systems development. It was described in Ziemann's work [50] and is based on the results of various interoperability research projects, combining concepts, from Service-oriented Architecture, Collaborative Business and Business Process Modelling, as shown in figure 2.

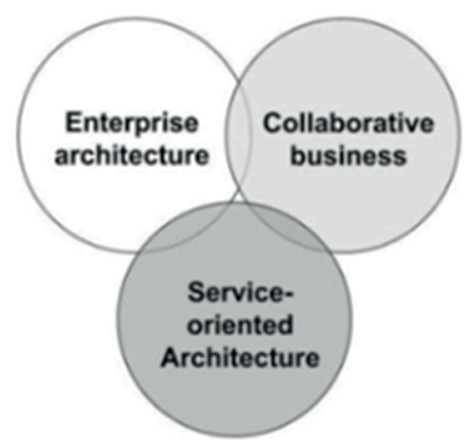

Figure 2: Development of collaborative business processes based on three research fields [50]. Source: Ziemann J. Architecture of Interoperable Information Systems. An Enterprise Model-Based Approach for Describing and Enacting Collaborative Businesss Processes, Wirtschaftsinformatik - Theorie und Anwendung

The AIOS represents a building model for development of interoperable systems, adjusting and extending their internal information systems systematically. Accordingly, Ziemans findings and studies represent a solid ground for further research and papers upon interoperability and organization architecture that enables further sustainable development and growth [50]. 


\title{
2.8. ERP Public Sector Implementation - Case 8
}

\author{
Yi Wan, Ben Clegg. Managing ERP, Interoperability Strategy and Dynamic Change \\ in Enterprises [51]
}

As recent trends in business and technology emphasized onto inter-organizational collaboration and information system that enhance them (Banker et al., 2010) [52], many companies recognized critical interdependencies influence among the firms, suppliers and customers, which cannot be described in terms of simple contractual exchanges, but involve the interactions and network effects with appropriate new enterprise paradigms, information technology (particularly Enterprise Resource Planning - ERP - systems), and interoperability strategies.

This paper presented preliminary findings and analysis from research into ERP systems and enterprise paradigms followed by inter-operational activities. It also combines critical and prescriptive perspectives as a necessary means of making its contribution to the practitioner's toolkit [51]. Authors in this study used the term "enterprise" to reflect the current phenomena whereby business activity is not always carried out by a single legal entity or by itself.

An enterprise is particularly defined as "... any entity irrespective of its legal form, which includes partnerships or associations that can be made up of parts of different companies, as well as regularly engaging in an economic activity." (European Commission, 2003) [51]. Banker, Chang, and Kao conducted evaluation of crossorganizational impacts of information technology through an empirical analysis [52]. The importance of such inter-firm relations has been recognized by the structural concepts of vertically integrated enterprises (Lynch, 2003; Joskow, 2003) [53] [51], extended enterprises (Powell, 1990; Davis and Spekman, 2004) [54] [55] and virtual enterprises (Byrne and Brandt, 1993; Goranson, 1999) [56] [57] and in the related technical support systems such as web-based Service Oriented Architecture (SOA), Platform as a Service (PaaS), and Software as a Service (SaaS) (Bass and Mabry, 2004; Torbacki, 2008; Candido et al., 2009) [58] [59] [51].

Regardless of arguments concerning the core competences (that affect the design and management of the enterprises structures) (Binder and Clegg, 2006) [60] [61], the "interconnectedness" of inter-firm (i.e. intra-enterprise) governance is criticized due to insufficient consideration and contribution to the impact of ERP systems on future enterprise structures with interoperability strategies and vice versa. Additionally, since current prevailing ERP systems are not able to support virtual enterprise structures, the authors have proposed a contingency term called "ERPIII" in this paper, so to describe a model of future agile enterprise management systems [51]. A summary of this research project, tried to contribute to the academia and practitioner understanding of the issues at play when ERP systems and interoperability strategies are introduced into the context of collaborative enterprise is demonstrated. Some findings were offered on how ERP systems could be used to effect dynamical changes in enterprise structures and their corresponding interoperability strategies, and were discussed with the aid of multiple case studies [51]. 
Considering changes and innovations to ERP systems and further development, authors proposed using the term "ERPIII" System. Additionally, they proposed an appropriate illustration to proposed change. ERPIII aim is to integrate enterprise operations within and across enterprise. Extending the supply functionality to external enterprises (generally vendor-affiliated companies or enterprises) for reducing cost, improving supply chain efficiency, and performing collaborative innovation based on ERPII applications, ERPIII enterprises are pushing the agenda to the next level of integrating the traditional ERP and ERPII functionalities to include customers and the sales side of the marketplace in general [51].

The end state of the ERPIII enterprise have to include communication between customers, the ERP organization and the extended supply chain with SOA, PaaS, SaaS, and Service Level Agreement (SLA) tools so that even suppliers would engage in the sales side of the marketplace. Moreover, ERPIII will create the "borderless enterprise" by bringing together a host of technology sources such as collaboration techniques, social media, internet-based technologies, could computing, smart information integration and synthesis, etc. [51]. Accordingly, enterprises in different circumstances may require particular preferable structures with corresponding ERP systems, so to satisfy their requirements. At the moment, this is a proposal framework model, based upon the literature review on ERP developments and two initial case studies. The paper represents a kind of work in progress, so further details about the concept testing, theory developing and data can be provided by the authors [51].

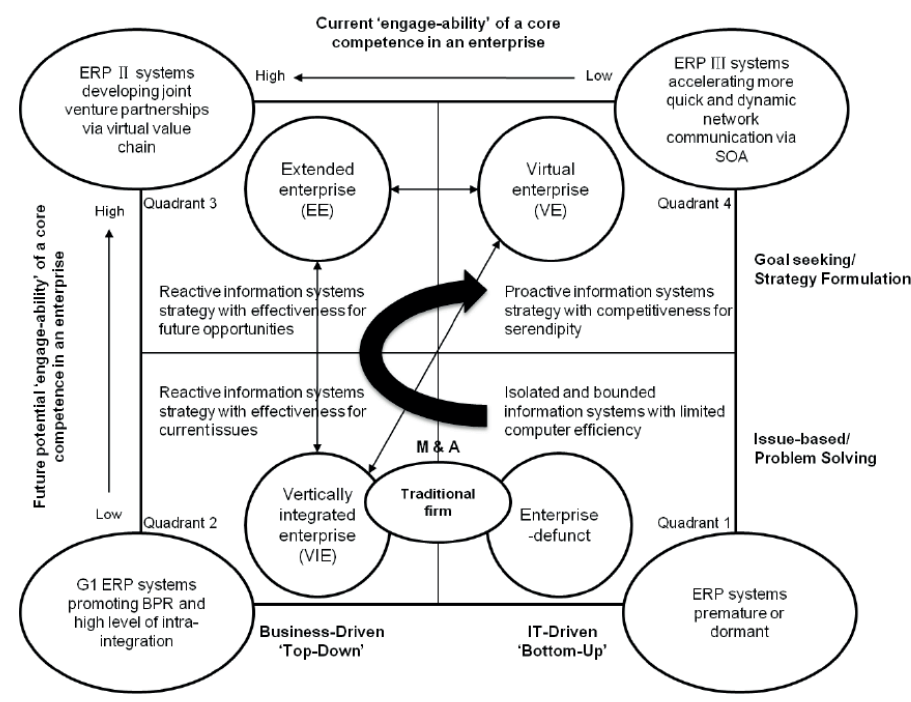

Figure 3: Novel sustainable conceptual framework for managing ERP systems development and dynamic enterprise strategies Source: Yi Wan, Ben Clegg. Managing ERP, Interoperability Strategy and Dynamic Change in Enterprises, Operations and Information Management Group, Aston Business School, Aston University, Birmingham, West Midlands, B4 7ET, UK [51]

Figure 3 shows the way how the above ideas can be combined in the context of global value chain and supply chain. Proposed enterprise types do not result from 
different strategies, but are actually part of the same overall business objective focused on inter-company cooperation. As presented in Figure 3, conceptual framework reveals ERP, ERPII, and ERPIII systems engage-abilities within three different interenterprise strategies and structures respectively, also ensuring a demonstration of cyclical transformation amongst one another [51].

In order to present and propose new generation of ERP systems, authors conducted case study analysis and focused on corresponding enterprise management patterns and interoperability strategies respectively for the purpose of achieving the agility and flexibility. It has not only investigated how ERP works in a VIE, EE, and VE context, but also uncovers developmental issues to present how one enterprise management type morphs into another using the DERG and the "IS strategy formulating" cycle [51].

The findings have implied that the design, operations and management of emergent inter-enterprise structures can be affected by preferable information systems (e.g. ERP). Different intra-enterprise strategies would compel the managers to development ERP systems to satisfy the IT requirements and newly organizational characteristics. Theoretical framework can be applied in any area referring to information systems, strategic enterprise structures, and operation management disciplines [51].

Authors' intention was to contribute to literature by filling the gaps of extant literature regarding the relations between ERP, inter-operational activities and dynamic intra-enterprise strategies. The results derived from this research also ensured practical implications that may help to guide enterprise managers for making better decisions within the inter-enterprise wide scope. Accordingly, with respect to future observations, studies, validations and development, "the induced novel sustainable dynamic framework can assist both academia and industrial managers to extend ERP modules and capabilities on the new platform" [51].

As a conclusion, the Zoomlion and Lanye case studies have revealed the future evolutionary trend between ERP systems and inter-firm management strategies within the context of the current global business market. These findings are part of an ongoing work, and this chapter demonstrated that the idea has strong potential contribution to make to both theory and practice [51].

\subsection{ERP Public Sector Implementation - Case 9}

Herve Panetto, Arturo Molina. Enterprise Integration and Interoperability in Manufacturing Systems: trends and issues, Computers in Industry [62]

Authors ensured insight into manufacturing integration, through Integration in Manufacturing (IiM), the first systemic paradigm to organize humans and machines as a whole system, not only at the field level, but also, at the management and corporate levels, to produce an integrated and interoperable enterprise system [62]. Contemporary networked businesses are meeting difficulties due to the lack of interoperability between enterprise systems. Accordingly, the role of research in the 
field is to create conditions of technological breakthrough to avoid that enterprise investment be simply pulled by the incremental evolution of IT offer.

The future tech and business are focused and relying on collaboration networks among companies, people and societies in order to generate shared knowledge and wealth. Authors considered a number of important enablers needed to support the creation of successful collaborative networks e.g. common reference models, effective interoperability mechanisms and approaches, supporting infrastructures based on open architectures, design and engineering methodologies to duplicate already successful cases, and standardized market technologies and tools [62].

Additionally, authors conducted a research and studied Enterprise Engineering models and tools needed for a seamless integration of Business and Manufacturing models, in order to completely describe the information aspects of an integrated manufacturing system [63]. It is to notice that enterprise integration is an essential component of enterprise engineering which concerns the set of methods, models and tools that one can use to analyze, to design and to continually maintain an enterprise in an integrated state. In the current industrial and economic context, enterprise systems need to be constantly and smoothly re-engineered to respond to changing market demand and technological evolution [62]. Considering the foundation of enterprise systems engineering, enterprise architecture became a ,toole to help stakeholders to manage system engineering and changes. Enterprise architecture is a challenging concept, not only an IT issue, but first of all a strategic and organizational challenge. When considering interoperability, the term integration is considered to go beyond interoperability to involve some degree of functional dependence [62].

Authors claim that interoperable systems can function independently, but when an integrated system loses significant functionality the services flow at whole is interrupted. An integrated set of systems must be interoperable (a key), but interoperable systems need not be integrated. There is also a compatibility issue, as well as question of systems interference. It is necessary to distinguish different concepts of compatibility, interoperability, and integration, because it influences conditions how to achieve them. In order to present the interdependence and mutual influences, authors presented also the degrees of integration and interoperability, necessary to ensure systems functioning [41]. As one of the most present and recognized models, they considered „Levels of Information Systems Interoperability" (LISI) [15], focused on the interoperability systems increasing levels of sophistication (Isolated systems, connected interoperability in a peer-to-peer environment, Functional interoperability in a distributed environment, Domain based interoperability in an integrated environment; Enterprise based interoperability in a universal environment.

In addition, authors proposed the Organizational Interoperability Maturity model (OIM), that extends the LISI model to the more abstract command and control support layers (Independent, Ad hoc, Collaborative, Integrated, Unified). Furthermore, the exchange flows type of content is also an issue. As a solution for this, authors proposed the NATO C3 Technical Architecture (NC3TA) Reference Model for Interoperability, [64] focused on technical interoperability, establishing interoperability degrees and sub-degrees (Unstructured Data Exchange, Structured 
Data Exchange, Seamless Sharing of Data, and Seamless Sharing of Information). The degrees were proposed to categorize how operational effectiveness could be enhanced by structuring and automating the exchange and interpretation of data [15]. At the conceptual level [44], the Level of Conceptual Interoperability Model (LCIM) addresses the level of conceptual interoperability that go beyond technical models like LISI. Systems interoperability is not only a technical problem (as stated by LISI or LCIM) but also deals with organizational issues (OIM).

These aspects of interoperability are coherent with the definitions proposed by the European Interoperability Framework [65], considering three aspects of interoperability (Organizational, Semantic, and Technical) [15] [62].

Authors also conducted research upon the Enterprise Modelling, Planning Systems, Manufacturing Execution Systems and business applications such as ERP systems, Enterprise Integration Engineering to integrate at all levels different types of e-technologies (Telecommunications, Internet/Intranet/Extranet, Database, Web Applications), e-applications (ERP - Enterprise Resource Planning, MES Manufacturing Execution System, SCI Supply Chain Integration, EPS-Electronic Procurement Systems, CRM - Customer Relationship Management, SRM - Supplier Relationship Management) and eservices (e-Supply, e-Engineering, e-Marketing, eBrokerage, e-Productivity, e- Factory) in order to create the concept of e-Enterprise [66].

Authors also analyzed semantics issues in manufacturing enterprise integration and interoperability, as well as Knowledge Management (KM) as an increasingly important source of competitive advantage for organizations, the capitalization and sharing of knowledge resulting from experience feedback are elements which play an essential role in the continuous improvement of industrial activities. Author's contribution deals with semantic interoperability and relates to the structuring and the formalization of an Experience Feedback (EF) process aiming at transforming information or understanding gained by experience into explicit knowledge. This paper takes domain ontology as a framework for the clarification of explicit knowledge and know-how, the aim of which is to get lessons learned descriptions that are significant, correct and applicable [67] [62].

Considering Manufacturing Enterprise Integration, two types describe the architecture: Type 1 - an architecture or physical structure of some component or part of the integrated system such as the computer system or the communications system and Type 2 - an architecture or structure of the project which develops the physical integration. Recent developments of ICT's (information and communication technologies), as well as turbulent market conditions are forcing small and medium size enterprises (SMEs) to radically change in order to adapt their way of undertaking business. Accordingly, they are leaving traditional practices and reorienting to ebusiness. Due to this context, new forms of collaboration have emerged, such as Collaborative Networks (CNs) [68] or virtual enterprises (VEs). In a collaborative networked environment (CNE), interoperability and integration enhance the competitive advantages of the CNs and their member organizations. In this context, they become critical goals towards achieving business objectives in a time, quality and cost effective manner [69]. 


\subsection{ERP Public Sector Implementation - Case 10}

Andrés Bozaa, Llanos Cuenca, Raúl Polera \& Zenon Michaelides The interoperability force in the ERP field [70]

Authors claimed and confirmed that ERP (Enterprise resource planning) systems participate in interoperability projects and this participation sometimes leads to new proposals for the ERP field. Furthermore, this papers' aim was to identify the role that interoperability plays in the evolution of ERP systems. ERP systems have been first identified within interoperability frameworks. Additionally, the initiatives in the ERP field were driven by interoperability requirements, and have been identified from two perspectives: technological and business. During the past few decades ERP has developed and evolved from classical ERP as information system integrators to a new generation of fully interoperable ERP. Interoperability is changing the way of running business, and ERP systems are changing to adapt to the current stream of interoperability [70].

By definition interoperability is the ability of two or more systems or components to exchange information and to use the information that has been exchanged. It is the ability of systems, units or forces to provide services to and accept services from other systems, units or forces, and to use the services so exchanged to enable them to operate effectively together. Interoperability can be considered, roughly speaking, as the ability of a system to use functionalities of another (possibly remote) system. Interoperability in enterprise applications is explained as the ability of a system or a product to work with other systems or products without special effort from the customer or user [70].

ERP systems as information systems (ISs) were designed to integrate and optimize business processes and transactions in a corporation by embracing different areas such as manufacturing, human resources, finance/accounting, sales, etc. They were universally accepted by the industry as a practical solution to achieve integrated enterprise ISs. In fact, those systems need continuous reviewing, development monitoring and enhancement, in order to meet user requirements [70]. Evolution of ERP systems have developed new systems over time thanks to ERP developers, who have identified and developed new functionalities for them. In particular cases and circumstances, those changes were planned and designed so to include new business processes in the ERP [70].

This paper aim was to identify the role of interoperability in the evolution of ERP systems. In order to support this, ERP systems have been first identified within interoperability frameworks. Additionally, new initiatives in the ERP area were driven by interoperability requirements and identified from two perspectives: technological and business. This paper deals with interoperability and describes ERP in the interoperability proposals, as well as the interoperability scope in ERP, reviews the proposals in the ERP field driven by interoperability, and consequently, summarize and conclude it [70]. 


\section{ERP and Interoperability Impacts}

ERP implementation and interoperability development throughout enterprise, planed, prepared and implemented as a project are basis for further activities. Ensuring timeframe, as well as organizational, financial and legal framework opens an opportunity for monitoring, management improvements and future developments. Also, in order to ensure project output and outcome, ERP and interoperability have to be considered complementary, parallel systems, serving the same objective.

\subsection{Expected Impacts}

ERP implementation and interoperability growth impact are significant change in public administration, their improvement and personalization, as well as its dissemination. This is directly linked to the work program and topic, improving innovation capacity and integration of new knowledge - strengthening the competitiveness and growth of organizations by developing innovations and meeting the needs of citizens. It ensures social and public change - growth and development through public service reform. There are also barriers and challenges, recognized in existing organizational framework, existing public services are not satisfying public needs, through lack of efficiency, efficacy, and low usage of contemporary ICT accomplishments.

$\mathrm{EU}$ is in need for further development and transformation of public services and the most of the member states need further development in this area. The key point is development of new services and upgrading existing public service system, as well as opening an area for research and studies, following to interaction of stakeholders and interoperability trends shown in analysis of state of the art. Recent studies and publications upon public administration reform needs are quite supportive to this project, as well as simplification trends in legislation on the EU level, so this project will bring another value to this initiative. Also, platform resulting from the project will enable future projects and development of new services in public sector.

\subsubsection{Key Impact - Interoperability as a Keyword}

According to Information Technology Vocabulary [17], interoperability is defined as "The capability to communicate and execute programs or transfer data to multiple functional units in a manner that requires from user to have little or no knowledge of the unique characteristics of those units". This is less strict definition, because program user can be another program, focusing on the technical side, so interoperability becomes an organizational issue. Interoperability is mostly described as the continuous potential to receive and send data between two or more interconnected units, with ensured communication quality level and negative influences excluded to the receiving and sending networks. This includes multiple functional relation, activities and continuous communication between multipleprovider, user, server, carrier and each role multiple connections. There are various interoperability modes, such as semantic, syntactic, cross-domain, search, open standards and post-facto interoperability. Public administration services aren't 
sufficient to satisfy growing needs, not efficient enough and not using available ICT accomplishments. Europe is facing transformation challenge, as well as structural reforms, efficiency growth needs, new working places, and particularly new technologies and innovation utilization.

Main purpose of this project is to ensure personalized public services development based on new technologies, in order to provide efficient, effective and quality public service to society. It also aims to modernize and simplify public administration - following EU, national and local needs for open citizen-centric public services. In addition to this, tax payers, EU and national organizations and institutions, as well as professional groups and associations, will be provided with more transparent services and systems, so to enable further development. Specific challenge of this topic is new insights in how to think of the systems and services combined with new technologies that will provide opportunities for innovative designs and transformation of public sector delivery.

Enterprise resource planning (ERP) systems participate in interoperability projects and this participation sometimes leads to new proposals for the ERP field. The aim of this paper is to identify the role that interoperability plays in the evolution of ERP systems. To go about this, ERP systems have been first identified within interoperability frameworks. Initiatives in the ERP field driven by interoperability requirements have been identified from two perspectives: technological and business. The ERP field is evolving from classical ERP as information system integrators to a new generation of fully interoperable ERP. Interoperability is changing the way of running business, and ERP systems are changing to adapt to the current stream of interoperability.

\subsubsection{Environment and Influences, Political and Legal Framework}

Institutional interoperability has significant impact on organizations and systems, raising issues of ownership and usability. The lack of interoperability regularly results in product standardization gaps during the design phase. Interoperability regularly has important economic consequences. Following to growing importance that interoperability have across the EU, throughout the market, society, organizations, institutions, covering each part of organizational life, EU institutions have ensured strong legal and institutional support as a legal and institutional framework.

There are not only political declarations, but also series of documents, regulations, directives as a basis for development and implementation of ERP and interoperability. In order to reach planned functionality, efficacy and efficiency, institutions have ensured framework for interoperability and therefore for further steps in ERP and/or other systems implementation. Since the mid 1990's EU Parliament, Commission and related institutions and organizations have prepared set of legal and political conditions, bringing interoperability into perspective, not only from the technical aspect, but also political and organizational, as the awareness upon political influence was raised. Additionally, there were set of expectations amongst interest groups, science and tech. 


\subsection{Measures to Maximize Implementation Impact}

In order to maximize implementation impact, there are necessary steps towards impact maximization. One of the key steps and activities is communication towards stakeholders, cooperatives, support, public and users of public services in general. When considering communication, there are strong evidences that dissemination have great impact onto various project segments and stakeholders.

Communication includes various types of reporting, as well as media and professional campaign, meetings, focused onto experts and expert area targeted, i.e. dissemination of information, in order to prepare public for the planned activities and processes.

Dissemination has strong influence, critical role and ensures communication to each project stakeholder and public awareness building. Also, it contributes to initiation of data base and data centers, and research points for further research. Cooperation and communication to public administration representatives as key stakeholders will ensure opening the critical chapter of the project - connection to public administration officers and ensuring their targeted education are another critical point of this project.

\subsection{Consultation of Stakeholders}

The most of stakeholders usually expressed the need for accurate, timely and overall information system for everyday decision-making and long term strategic planning. Many public sector IT environments, usually disparate, non-integrated systems, simply weren't able to ensure such data. Public sector ERP implementation resulted in similar experiences. The major part of key decision makers declared that their organization couldn't complete the ERP project within the original timeframe, ranging from 6 to 12 months. ERP and interoperability are taking into account the social, political and legal factors influencing new ICT technology based public services, include inputs and feedbacks from citizens and civil servants, and identify the ways how they can contribute to modernizing policies and innovative services of general interest. presumptions and importance of uniting ERP engage-abilities and interoperational activities within the context of dynamic collaborative enterprises, as well as investigating how ERP systems cater for three enterprise forms and the resultant interoperability strategies.

Previous findings suggest that the design and governance of newly enterprise structures and interoperability strategy can be affected by preferable information systems besides of the core competence. Furthermore, with the implications from this paper, practitioners will be better able to steer their enterprise strategies and improve the operational performance through the inter-firm collaboration and ERP systems implementation. Most of the public sector enterprises mentioned and analyzed were generally interested and gave similar reasons for exploring an ERP solution. They need to replace legacy information technology (IT) systems that lack needed functionality, flexibility, and, in many cases, can no longer be supported. 


\subsection{Interoperability Influence to Public Sector ERP Implementation}

The most of organizations were unsatisfied with an unrealistic initial timeline, some of them reported a timeline of less than one year, but mostly reported an original timeline of two years and more. Common causes for timeline breaks were the following: lack of adequate preparation, lack of the knowledge and experience needed to ask the right questions, inability to foresee and mitigate potential challenges and an inability to gauge the impact of trade-offs along the way.

It's important to note that delays are not necessarily bad, especially if the original timeline estimates are unrealistic. But there are significant financial downsides associated with delays, including lost productivity, employee costs and lost opportunity costs from enterprise systems disruption. Prudent delays, however, may be preferable to striving to meet unrealistic targets. But organizations must weigh decisions to delay carefully. Most ERP project budget overruns are directly linked to delays in the implementation timeline.

ERP implementation and institutional interoperability development will ensure various benefits:

- Public services tailored for individual users,

- Faster and cheaper interaction with government,

- New businesses opportunity based on available public sector data and services,

- Easier development of sophisticated services and products needed by businesses and citizens and

- Improved public sector business processes based on modern ICT technologies.

\section{Related Works and Contemporary References}

This area has growing influence and importance, as "new generation" ERP implementation starts with series of changes throughout entire enterprise organizations.

Recently, many American, European and Asian authors and groups, as well as institutions (faculties, institutes, organizations, corporations, consultants' agencies etc.) are putting additional efforts in contributing to this topic enlightening and giving us an adequate insight into this "not so new", but definitely relevant and important area and discipline to study.

Croatian authors, mostly from the IT area of expertise contributed to this area with interdisciplinary researches. Additionally, their timing was related mostly with European - UK and American authors and findings. Goran Hajdin and Neven Vrček (2010) have described set of methodologies for measuring e-government development in their paper with the same name, upon the Croatian case (2010) [3].

Rainer Sommer (2011) conducted various studies upon public sector ERP Implementation, and his paper upon middle-management role successfully described impact this management segment has onto enterprise in ERP implementation [1]. 
William Wagner and Yvonne Lederer Antonucci have analyzed the Imagine PA Public Sector ERP Project (2004) and ERP implementation across Commonwealth of Pennsylvania, as well as local and federal aspect of this project and related activities [14].

Mohammad Reza Moohebat, Asefeh Asemi, Mohammad Davarpanah Jazi conducted a comparative study of Critical Success Factors (CSFs) in implementation of ERP in developed and developing countries (2011) [22].

Jukka Hemilä (2002) from Finland have analyzed and described information technologies for value network integration (2002), analyzing the case study InElogproject (Incap E-logistics) of VTT Industrial Systems [13].

Jörg Ziemann in his doctoral work Architecture of Interoperable Information Systems. An Enterprise Model-Based Approach for Describing and Enacting Collaborative Business Processes (2010) analyzed and presented architecture of interoperable information systems throughout contemporary enterprise concept, considering ERP, as well as interoperability [50].

Wided Guédria, David Chen and Yannick Naudet successfully analyzed and described a maturity model for enterprise interoperability, including 4 stages or levels that may be presented and/or measured (2009) [49].

Yi Wan and Ben Clegg (2011) have conducted a study of ERP, interoperability strategy and dynamic change in enterprises in their paper Managing ERP, Interoperability Strategy and Dynamic Change in Enterprises [51].

Herve Panetto and Arturo Molina analyzed and described trends and issues in enterprise integration and interoperability in manufacturing systems (2008) [62].

Andrés Bozaa, Llanos Cuencaa, Raúl Polera and Zenon Michaelides have analyzed and described interoperability force in the ERP field (2014) [70].

\section{Trends in ERP Implementation and Relations to Interoperability}

Integration in manufacturing was the first systemic paradigm to organize humans and machines as a whole system, not only at the field level, but also, at the management and corporate levels, to produce an integrated and interoperable enterprise system. Business process software systems are now available to meet the requirements of ICT supported and covered integration.

Key issues remain between the enterprise corporate level and the manufacturing level, so that management and operation decisions within a closed loop are facilitated to pace the production according to the life-cycle dynamics of the products, processes and humans inside and outside the enterprise.

Contemporary networked business includes "regular" difficulties due to the lack of interoperability between enterprise systems. The role of research in the field is to create upstream conditions of technological breakthrough to avoid that enterprise investment be simply pulled by the incremental evolution of IT offer. However, the future relies on collaboration networks that can be created among companies, people and societies in order to generate shared knowledge and wealth.

A number of important enablers are needed to support the creation of successful collaborative networks e.g. common reference models, effective interoperability 
mechanisms and approaches, supporting infrastructures based on open architectures, design and engineering methodologies to instantiate/duplicate already successful cases, and standardized market technologies and tools.

Enterprise Engineering models and tools are needed for a seamless integration of Business and Manufacturing models, in order to completely describe the information aspects of an integrated manufacturing system. However, up to date, although some high level standards in the area of Enterprise modelling and integration are available; they are not yet widely recognized as such and not used in industry.

Future scenarios place Information and Communication Technologies to be core in new developments. Digital megatrends such as: e-Tailing, e-Government, Entertainment on demand, virtual education and a wide set of online services (finance, publishing, marketing) will be part of everyone life's.

\section{Conclusion}

Following the presented and analyzed case studies, findings in various interdisciplinary studies and researches, there are strong evidences upon the growing influence, interconnection and impact of ERP implementation and interoperability, in public sector, as well as in private sector, regardless of the specific characteristics and conditions. Furthermore, issues related to ERP success in implementation are mostly the similar with the interoperability, as there are practically the similar conditions, constructs, structures and strategies.

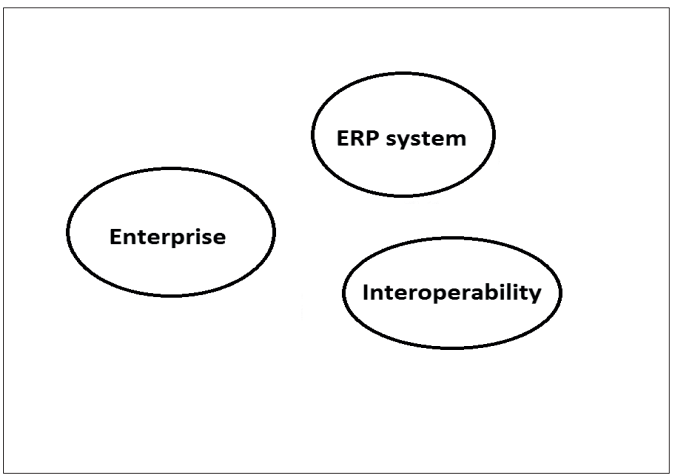

Figure 4: ERP, Enterprise and Interoperability mutual interdependence and strong influence.

Public sector ERP implementation started a bit later than in private sector, following it less intensive and in slow speed, due to various reasons. Yet, according to slow dynamics and low intensity, ERP implementation have shown a kind of predictability and according to public sector legal and organizational framework, decisions were brought upon consensus and stakeholders influence. When compared to private sector, ERP implementation and interoperability intensification have not enough indicative experiences, as they are less numerous, intensive and with less feedback. Regardless of those facts, public sector has adopted the most of ERP solutions from private sector, with respect to specific differences, structure, culture 
and dynamics. Contemporary business environment and tech development are pushing the ERP implementation agenda and interoperability development towards ERP III and/or newer versions. Considering the technology, as well as social and economic development, researchers have to take into account new trends in each of component.

Quantum computers and emerging technologies are supportive to interoperability development and "ERP III" solutions. Yet, there are still timeline gaps and issues in planning and realization of the most appropriate solution. Connecting ERP with enterprise and interoperability becomes priority and considering ERP III and new circumstances, ICT development and standardization, as well as interoperability growth and development, there are reasonable expectations for mutual interdependence and strong influence, as shown in figure 4.

\section{References}

[1] R. Sommer, Public Sector ERP Implementation, Successfully Engaging Middle-Management, 2011, IBIMA Publishing, Vol. 2011 Art. ID 162439, Available at:

http://www.ibimapublishing.com/journals/CIBIMA/cibima.html Accessed: February 2016

[2] G. Blick, T. Gulledge and R. Sommer, Defining Business Process Requirements for Large-Scale Public Sector ERP Implementations: A Case Study, 2004 Proceedings of the European Conference on Information Systems, Available at: https://pdfs.semanticscholar.org/9b7f/a4a12935583a2fc0ffacde 24688cbebc75e2.pdf, Accessed: February 2016

[3] G. Hajdin, N. Vrček, 2010, Methodologies for Measuring E-Government Development: The Croatian Case // Proc. The 21st Central European Conference on Information and Intelligent Systems / B. Aurer, M. Bača, M. Schatten, editor(s). Faculty of Organization and Informatics, 319-325 Varaždin, 2010. Available at: http://archive.ceciis.foi.hr/app/index.php/ceciis/2010/paper/view/302 Accessed: February 2016

[4] Central State Administrative Office for e-Croatia 2009, e-Croatia, Implementation Plan for Year 2009, Available at: at http://ehrvatska.hr/sdu/hr/ ProgramEHrvatska/Provedba/StrategijeIProgrami/categoryParaGraph/0111 7/document/Plan_provedbe_programa_e_Hrvatska_za_2009 konacni_tekst.pdf, In G. Hajdin, N. Vrček, Methodologies for Measuring E-Government Development... // Available: http://archive.ceciis.foi.hr/app/index.php/ceciis/2010/paper/view /302 Accessed: February 2016 
[5] Central State Administrative Office for e-Croatia 2008, e-Croatia Implementation Plan for Year 2008, at http://e-hrvatska.hr/sdu/hr/Program EHrvatska/Provedba/StrategijeIProgrami/categoryParaGraph/01113/docum ent/ Plan_provedbe_Programa_e_Hrvatska_za_2008.pdf, In G. Hajdin, N. Vrček, Methodologies for Measuring E-Government Development... // Available at: http://archive.ceciis.foi.hr/app/index.php/ceciis/2010/paper/view/302 Accessed: February 2016

[6] M. D. West: Global E-Government 2007, at http://www. insidepolitics.org/ egovt07int.pdf, In G. Hajdin, N. Vrček, Methodologies for Measuring EGovernment Development... // Available at: http://archive.ceciis.foi.hr/app/ index.php/ceciis/2010/paper/view/302 Accessed: February 2016

[7] CIO Council: Best Practices Committee, 2002 Value Measuring Methodology, Available at http://www.cio.gov/Documents/Value Measuring_Methodology_HowToGuide_Oct_2002.pdf, In G. Hajdin, N. Vrček, Methodologies for Measuring E-Government Development... // Available at: http://archive.ceciis.foi.hr/app/ index.php/ceciis/2010/paper/view/302 Accessed: February 2016

[8] E-Business Watch 2008, Methodology, Available at http://www.ebusinesswatch.org /about/methodology.htm, In G. Hajdin, N. Vrček, Methodologies for Measuring E-Government Development...// Available at: http://archive.ceciis.foi.hr/app/index.php/ceciis/2010/paper/view/302 Accessed: February 2016

[9] United Nations 2010, United Nations e-Government Survey 2010, available at http://unpan1.un.org/intradoc/groups/public/documents/UNDPADM/UNPAN 038-853.pdf, In G. Hajdin, N. Vrček, Methodologies for Measuring E-Government Development... // Available at: http://archive.ceciis.foi.hr/app/index.php/ceciis /2010/paper/view/302 Accessed: February 2016

[10] United Nations 2008, UN e-Government Survey 2008, available at http://unpan1.un.org/intradoc/groups/public/docudocum/UN/UNPAN0286 07.pdf, In G. Hajdin, N. Vrček, Methodologies for Measuring EGovernment Development... // Available at: http://archive.ceciis.foi.hr/app/index.php/ ceciis/2010/paper/view/302 Accessed: February 2016

[11] Republic of France Premier Minister ADAE: MAREVA methodology guide: Analysis of the value of ADELE projects, available at http://ec.europa.eu/ information_society/activities/egovernment/docs/pps/2 mareva methodology_guide.ppt, In G. Hajdin, N. Vrček, Methodologies for Measuring E-Government Development... // Available at: 
http://archive.ceciis.foi.hr/app/index.php/ceciis/ 2010/paper/view/302 Accessed: February 2016

[12] P. Rothing 2004, WiBe 4.0 Measuring Impact, Available at http:// www.epractice.eu/ files/ 03_Peter_Röthig.pdf, In G. Hajdin, N. Vrček, Methodologies for Measuring E-Government Development... // Available at: http://archive.ceciis.foi.hr/app/ index.php/ceciis/2010/paper/view/302 Accessed: February 2016

[13] J. Hemilä 2002, Information technologies for value network integration, VTT Industrial Systems, VTT Technical Research Centre of Finland, Available at: https://www.semanticscholar.org/paper/Informationtechnologies-for-value-networkHemil\%C3\%A4/a032d6997c33d1b1b1875b0056fe6144e81d190e, Accessed: February 2016

[14] [W. Wagner, Y. Lederer Antonucci, 2004 An Analysis of the Imagine PA Public Sector ERP Project, Villanova University, Villanova, PA US, 2004 Available at: https://www.researchgate.net/publication/221177150 An_analysis_of_the_imagine_PA_public_sector_ERP_project Accessed: February 2016

[15] C-A Information Technology Vocabulary. ISO/IEC 2382-1:1993- Part 1: Fundamental terms Online Available at: https://www.iso.org/cate/d7229.html Accessed: February 2016

[16] D. Boyer, "ERP Implementation: Managing the Final Preparation and GoLive Stages", 2001. Government Finance Review, December 2001, pp. 4144. Online Available at: https://www.questia.com/magazine/1G181530557/erp-implementation-managing-the-final-preparation Accessed: February 2016

[17] E. Watson, S. Vaught, D. Gutierrez; D. Rinks, "ERP Implementation in State Government", 2003. Annals of IT Case Studies, Idea Group Inc. Available at: https://www.igi-global.com/article/erp-implementation-stategovernment/44549 Accessed: February 2016

[18] S. I. Chang, G. Gable, E. Smythe, G. Timbrell. "A Delphi Examination of Public Sector ERP Implementation Issues, 2001, Proceedings of the International Computer Information Systems, Brisbane, Australia, Online Available at:

https://www.researchgate.net/publication/27466296_A_Delphi_examinatio n_of_public_sector_ERP_implementation_issues Accessed: February 2016

[19] J. Makulowich, "Enterprise Resource Planning: It's in the Morphing”, 1999, Washington Technology, USA, Available at: https://washingtontechnology.com /articles/1999/04/22/enterpriseresource-planning-it39s-in-the-morphing.aspx Accessed: February 2016 
[20] N. G. Sanchez, L. E. Bernal Determination of Critical Success Factors in Implementing an ERP System: A Field Study in Mexican Enterprises. 2007 Ed. by: Information Technology for Development; 293-309. Vol. 13. 106 International Journal of Advancements in Computing Technology Vol. 2, No 5. Available at:

https://onlinelibrary.wiley.com/doi/pdf/10.1002/itdj.20075 Access: February 2016

[21] A. Tolk, Beyond Technical Interoperability - Introducing a Reference Model for Measures of Merit for Coalition Interoperability. 2003. In Proceedings of the 8th International Command and Control Research and Technology Symposium (ICCRTS), Washington, DC, Washington DC: Command and Control Research Program (CCRP), Available at: www.dtic.mil/get-tr-doc/pdf?AD=ADA-466775 Accessed: February 2016

[22] M. Moohebat, A. Asemi, M. A. Davarpanah Jazi, Comparative Study of Critical Success Factors (CSFs) in Implementation of ERP in Developed and Developing Countries, In International Journal Of Advancements In Computing Technology, 2010. Available at:

https://www.researchgate.net/publication/216842768_A

Comparative_Study_of_Critical_Success_Factors_CSFs_in_Implementatio n_of_ERP_in_Developed_and_Developing_Countries Accessed: February 2016

[23] Gartner. In The Gartner Glossary of Information Technology Acronyms and Terms. Edited by: Gartner: 1-395 2004. Available at: https:/www.gartner.com/it-glossary/ Accessed: February 2016

[24] P. Hawking, A. Stein, S. Foster, Revisiting ERP systems: benefit realization. 2004 In 37th International Conference on System Sciences; Hawaii; Available at:

https://www.researchgate.net/publication/224745919_Revisiting_ERP_syst ems_Benefit_realization Accessed: February 2016

[25] E. W. T. Ngai, C. C. H. Law, F. K. T. Wat. Examining the critical success factors in the adoption of enterprise resource planning. 2008, Computers in Industry; 548-564. Abstract Available at:

https://dl.acm.org/citation.cfm?id=1374989 Accessed: February 2016

[26] Statistics over IT projects failure rate on World Wide Web Available at: http://www.it-cortex.com/Stat_Failure_Rate.htm Accessed: February 2016

[27] J. Esteves-Sousa, J. Pastor-Collado, Towards the unification of critical success factors for ERP implementations, 2000. In Proceedings of the 10th Annual Business Information Technology (BIT) Conference; Manchester, UK, Available at: https:/www.researchgate.net/publication/228841545_Towards_the_Unific 
ation_of_Critical_Success_Factors_for_ERP_Implementations Accessed: February 2016

[28] M. L. Markus, C. Tanis, P. C. Van Fenema, Enterprise resource planning: multisite ERP implementations. Communications of the ACM, 1999 43:42-46. Available at:

https://www.researchgate.net/publication/234773112

Enterprise_resource_planning_multisite_ERP_implementations? $\mathrm{ev}=\mathrm{auth} \_\mathrm{p}$ ub Accessed: February 2016

[29] B. Wong, D. Tein, Critical Success Factors for ERP Projects. In Proceedings of the National Conference of the Australian Institute of Project Management: 2003. Available at: https://pdfs.semanticscholar.org/76ea/2de0dd98e9f52babe21 63e8d8f78d23420cf.pdf Accessed: February 2016

[30] C. M. Chituc, C. Toscano, A. Azevedo, Interoperability in Collaborative Networks: major independent and domain initiatives - The case of shoe manufacturing domain. $2008 \mathrm{In}$ : Special issue on Enterprise Integration and Interoperability in Manufacturing Systems, A. Molina and H. Panetto (Eds). Computers In Industry, 59/5, Elsevier, Abstract Available at: https://dl.acm.org/citation.cfm?id=1391062 Accessed: February 2016

[31] J. K. Leidecker, A. V. Bruno. Identifying and using critical success factors. Long Range Planning 1984 Available at:

https://pdfs.semanticscholar.org/5ae4/ 14a5b0d914640004e35efe2442e87094e020.pdf Accessed: February 2016

[32] A. Ramaprasad, J. Williams. The utilization of critical success factors: a profile. 1998 In 29th Annual Meeting of the Decision Sciences Institute; LasVegas, USA. In M. Moohebat, A. Asemi, M. A. Davarpanah Jazi, Comparative Study of Critical Success Factors (CSFs) in Implementation of ERP in Developed and Developing Countries, 2010, In International Journal Of Advancements In Computing Technology, Available at: https://www.researchgate.net/publication/216842768

_A_Comparative_Study_of_Critical_Success_Factors_CSFs_in_Implemen tation_of_ERP_in_Developed_and_Developing_Countries Accessed: February 2016

[33] J. F. Rockart, Chief executives define their own data needs. Harvard Business Review, 57:81. 1979 Available at:

https://www.researchgate.net/publication/ 13000263_Chief_Executives_Define_Their_Own_Data_Needs Accessed: February 2016

[34] M. H. Rasmy, A. Tharwat, S. Ashraf, Enterprise Resource Planning (ERP) Implementation in the Egyptian Organizational Context. Citeseer, 2005, In European and Mediterranean Conference on Information Systems; Cairo, Egypt. Available at: 
http://citeseerx.ist.psu.edu/viewdoc/summary?doi=10.1.1.114.3468 Accessed: February 2016

[35] L. Fang, S. Patrecia, Critical Success Factors in ERP Implementation: Jönköping International Business School: 2005. Available at: http://www.diva-portal.org/smash/get/diva2:3922/fulltext01.pdf Accessed: February 2016

[36] C. P. Holland, B. Light, A critical success factors model for ERP implementation. IEEE Software 16:30-36. 1999 Available at: https://pdfs.semanticscholar.org/db19/7d760ed5e880ea5c872af7d1069b39 085e49.pdf Accessed: February 2016

[37] Z. Huang, P. Palvia, ERP implementation issues in advanced and developing countries. Business Process Management Journal pp. 276-284. 2001 Available at: https://libres.uncg.edu/ir/uncg/f/P_Palvia_ERP_2001.pdf Accessed: February 2016

[38] J. Rajapakse, P. B. Seddon, Why ERP may not be Suitable for Organizations in Developing Countries in Asia. In Proceeding of Information systems research seminar in Scandinavia-IRIS. Sweden, 2005 Available at: http://www.pacis-net.org/file/2005/121.pdf Accessed: February 2016

[39] W. Guedria, Y. Naudet, D. Chen, Interoperability maturity models Survey and Comparison. In: The 3rd IFAC/IFIP, OTM workshop, EI2N 2008 (Enterprise Integration, Interoperability and Networking), Mexico, 2008 Available at: https://pdfs.semanticscholar.org/13ca/a7470cf6bc44903fb993a5880997ffce 091d.pdf Accessed: February 2016

[40] Interop NOE (IST-2004-508011), ATHENA (2004 to 2007), “Advanced Technologies for Interoperability of Heterogeneous Enterprise Networks and their Application", IST-2004-507849) or R4eGov (IST-2004-026650). Germany, 2007. Available at: https://www.tandfonline.com/doi/abs/10.1080/17517575.2013. 879213? scroll=top\&needAccess $=$ true $\&$ journalCode=teis 20 Accessed: March 2016

[41] H. Panetto, Towards a Classification Framework for Interoperability of Enterprise Applications. 2007, International Journal of CIM, 20/8, 727 740, Taylor \& Francis, In: Special issue on Enterprise Integration and Interoperability in Manufacturing Systems, A. Molina and H. Panetto (Eds). Computers In Industry, 59/5, May 2008, Elsevier Available at: https://hal.archives-ouvertes.fr/hal-00116336/document Accessed: March 2016 
[42] C4ISR Interoperability Working Group, Levels of information systems interoperability, Tech. report, US Department of Defense, Washington DC, USA 1998. Available at:

http://www.dtic.mil/dtic/tr/fulltext/u2/a348567.pdf Accessed: March 2016

[43] T. Clark and R. Jones, Organizational Interoperability Maturity Model for C2, In Proceedings - Command And Control Research And Technology Symposium (CCRTS), June 29, July 1, Newport, RI, USA, 1999. Available at:

https://pdfs.semanticscholar.org/15c9/6e5f20012f79b029d2269fa73fe8013 86268.pdf Accessed: March 2016

[44] A. Tolk, J. A. Muguira, The levels of conceptual interoperability model. 2003 In: Fall Simulation Interoperability Workshop, USA 2003. Available at:

https://pdfs.semanticscholar.org/f655/af160f630b9be8dbab986f6a96953aa 3e986.pdf Accessed: March 2016

[45] ATHENA. Advanced Technologies for Interoperability of Heterogeneous Enterprise Networks and their Applications, FP6-2002-IST1, Integrated Project Proposal, EU 2003. Available at:

https://cordis.europa.eu/project/rcn /72762_en.html Accessed: March 2016

[46] International Organization for Standardization and International Electro technical Commission, ISO/IEC 15504 Software Process Improvement and Capability Determination Model (SPICE), 2001. Available at: https://www.iso.org /obp/ui/\#iso:std:iso-iec:ts:15504:-8:ed-1:v1:en Accessed: March 2016

[47] Method Integrated Team. Standard CMMI Appraisal Method for Process Improvement (SCAMPI), Version 1.1: Method Definition Document Members of the Assessment, 2001. Available at: https://resources.sei.cmu.edu/asset_files/ Handbook/2001_002_001_13766.pdf Accessed: March 2016

[48] Y. Naudet, W. Guédria, D. Chen, Systems Science for Enterprise Interoperability. In: IESA 2009 workshops, 5th International Conference Interoperability for Enterprise Software and Applications, Beijing, China 2009. Available at:

http://www.academia.edu/1401684/Systems_Science_for_ Enterprise_Interoperability Accessed: March 2016

[49] L. Von Bertalanfy, General System Theory: Foundations, Development, Applications. Georges Braziller, Inc., New York USA, 1968. Available at: https://monoskop.org/images/7/77/Von_Bertalanffy_Ludwig_General_Syst em_Theory_1968.pdf Accessed: March 2016

[50] J. Ziemann, Architecture of Interoperable Information Systems. An Enterprise Model-Based Approach for Describing and Enacting 
Collaborative Businesss Processes, Wirtschaftsinformatik - Theorie und Anwendung, Bd. 23, Germany, 2010. Available at: https:/www.researchgate.net/publication/235892886 Architecture_of_Interoperable_Information_Systems_An_enterprise_Model-based_Approach_for Describing_and_Enacting_Collaborative_Business_Processes Accessed: March 2016

[51] Y. Wan and B. T. Clegg, 'Managing ERP, Interoperability Strategy and Dynamic Change in Enterprises' POMS 22nd Annual Conference. Apr. 29 - May 2. Reno, Nevada, USA, 2011. Available at: https://www.researchgate.net/ publication/266464946_0200612_Managing_ERP_Interoperability_Strategy_and _Dynamic_Change_in_Enterprises Accessed: March 2016

[52] R. D. Banker, H., Chang and Y. Kao, Evaluating cross-organizational impacts of information technology-An empirical analysis. 2010 European Journal of Information Systems, 19, 153-167. USA, 2010 Available at: https://www.tandfonline.com/doi/abs/10.1057/ejis..9 Accessed: March 2016

[53] R. Lynch, Corporate strategy. 3rd ed., Financial Times. USA 2003. Available at: http://www.global-strategy.net/homepage/professor-richardlynch-profile/ Accessed: March 2016

[54] W. W. Powell, Neither market nor hierarchy: Network forms of organization. Research in Organizational Behavior, pp. 295-336.12, USA 1990. Available at: http://www.strategie-aims.com/events/conferences/9xiveme-conference-de-1-aims/communications/713-neither-market-norhierarchy-or-network-the-emerging-bazaar-governance/download Accessed: March 2016

[55] E. W. Davis, R.E. Spekman, The extended enterprise: Gaining competitive advantage through collaborative supply chains. London: Financial Times Prentice-Hall. USA, 2003. Available at: https://epdf.tips/the-extendedenterprise-gaining-competitive-advantage-through-collaborative-supp.html Accessed: March 2016

[56] J. A. Byrne and R. Brandt, The virtual corporation. Business Week, pp. 3641. Feb. 8, USA, 1993. Available at:

https:/www.bloomberg.com/news/articles /1993-02-07/the-virtualcorporation Accessed: March 2016

[57] H. T. Goranson, The agile virtual enterprise: Cases, metrics, tools. Quorum Books, Greenwood Publishing Group, Inc. USA, 1999. Online Available at:

file:///C:/Users/Korisnik/Downloads/Agile+Virtual+Enterprises+Excerpt.p df Accessed: March 2016 
[58] T. Bass and R. Mabry, Enterprise architecture reference models: A shared vision for Service-Oriented Architectures. IEEE MILCOM, 1-8., 2004. Abstract Online Available at:

https://www.semanticscholar.org/paper/Enterprise-Architecture-ReferenceModels\%3A-A-Shared-Bass-Mabry/9fc2d81115dc

641fba8fcbaec0fce8536b9c7d4e Accessed: March 2016

[59] W. Torbacki, SaaS - direction of technology development in ERP/MRP systems. Archives of Materials Science and Engineering, 31(1), 57-60. 2008. In Y. Wan, and B.T. Clegg, 'Managing ERP, Interoperability Strategy and Dynamic Change in Enterprises' Available at: https://www.researchgate.net/publication /266464946_0200612_Managing_ERP_Interoperability_Strategy_ and_Dynamic_Change_in_Enterprises Accessed: March 2016

[60] M. Binder, B. T. Clegg, “A conceptual framework for enterprise management". International Journal of Production Research, 44(18-19), 3813-3829, 2006. Available at: https://www.tandfonline.com/doi/abs/10.1080/00207540600786673 Accessed: March 2016

[61] M. Binder and B. Clegg, Designing and managing collaborative enterprises in the automotive industry. International Journal of Logistics Research and Applications, 10(2), pp 135-152. USA, 2007. Available at:

https://www.researchgate.net/profile/Ben_Clegg/publication/200029730_D esigning_and_managing_collaborative_enterprises_in_the_automotive_ind ustry/links/0a 85 e52 e65d56e4afe000000/Designing-and-managingcollaborative-enterprises-in-the-automotive-industry.pdf Accessed: March 2016

[62] H. Panetto, A. Molina, Enterprise Integration and Interoperability in Manufacturing Systems: trends and issues. Computers in Industry, 59 (7), pp.641-646. Elsevier, Netherlands 2008 Available at: https://hal.archivesouvertes.fr/hal-00259678 Accessed: March 2016

[63] F.B. Vernadat, Enterprise Modeling and Integration (EMI): Current Status and Research Perspectives. Annual Reviews in Control. 26/1, 15-25, 2002 Online Available at: https://www.sciencedirect.com/science/article/pii /S1367578802800062 Accessed: March 2016

[64] C3 Technical Architecture (NC3TA) NATO Allied Data Publication 34 (ADatP-34). NATO, C3 Technical Architecture (NC3TA), Vers. 4.0, 2003 In H. Panetto, A. Molina, Enterprise Integration and Interoperability in Manufacturing Systems: trends and issues. Computers in Industry, 59 (7), pp.641-646. Elsevier, Netherlands 2008 Available at: https://hal.archivesouvertes.fr/hal-00259678 Accessed: March 2016

[65] EIF, European Interoperability Framework for pan-European eGovernment Services, Interoperable Delivery of European e-Government 
Services to public Administrations, Businesses and Citizens (IDABC), November, Luxembourg 2004. Available at: http://ec.europa.eu/idabc/en/document/2319/5644.html Accessed: March 2016

[66] A. Molina, R.Mejía, N.Galeano, T. Najera, M. Velandia, The HUB as an enabling IT strategy to achieve Smart Organizations, Chapter III in Integration of ICT in Smart Organizations, Mezgar I. (Editor), pp. 64-95, ISBN: 1-59140-390-1 Idea Group Publishing, 2006. In H. Panetto, A. Molina, Enterprise Integration and Interoperability in Manufacturing Systems: trends and issues. Computers in Industry, 59 (7), pp.641-646. Elsevier, Netherlands 2008 Available at: https://hal.archivesouvertes.fr/hal-00259678 Accessed: March 2016

[67] F. B.Kamsu, T.Coudert, L. Geneste, Knowledge Formalization in Experience Feedback Processes: An Ontology-Based Approach. 2008 In H. Panetto, A. Molina, Enterprise Integration and Interoperability in Manufacturing Systems: trends and issues. Computers in Industry, 59 (7), pp.641-646. Elsevier, Netherlands Available at: https://hal.archivesouvertes.fr/hal-00259678 Accessed: March 2016

[68] A. Molina, H. Panetto, D. Chen, L. Whitman, V.Chapurlat, F.B. Vernadat Enterprise Integration and Networking: Challenges and Trends. Studies in Informatics and Control, 16/4. 353-368., Informatics and Control Publications ISSN 1220-1766 December, UK 2007 Available at: http://citeseerx.ist.psu.edu/viewdoc /download?doi=10.1.1.617.9396\&rep=rep1\&type=pdf Accessed: March 2016

[69] Interoperability Research for Networked Enterprises Applications and Software, FP6-IST 508011 (Interop NoE), Available at: http://www.interop-vlab.eu / Germany, 2007. Accessed: March 2016

[70] A. Bozaa, L. Cuenca, R. Polera and Z. Michaelides. The interoperability force in the ERP field pp 257-278 Enterprise Information Systems Vol. 9, Is. 3, 2015, Publ. online: 9 Jan 2014 Research Centre on Production Management and Engineering (CIGIP), Universitat Politècnica de València, Camino de Vera S/N, Valencia, Spain; University of Liverpool, UK 2015 Online Available at: https://dl.acm.org/citation.cfm?id=2884767 Accessed: March 2016 